\title{
Wave Spectrum Based Fatigue Analysis for Mediterranean Sea, Black Sea and Aegean Sea

\author{
Fuat Kabakçıoğlu ${ }^{1 *}$ and Ertekin Bayraktarkatal ${ }^{2}$ \\ ${ }^{I}$ Department of Naval Engineering, RMK Marine Shipyard, Tuzla, İstanbul, Turkey
} \\ ${ }^{2}$ Department of Naval Architecture and Marine Engineering, İstanbul Technical University, Istanbul, 34469, Turkey
}

(Manuscript Received March 27 2013; Revised April 25, 2013; Accepted May 28, 2013)

\begin{abstract}
In this study, wave spectrum based fatigue analyses are studied for Turkey's adjacent coastal seas by using Maestro finite element analyzing software. Palmgren-Miner's method is used to obtain the fatigue safe life time. Palmgren-Miner's method was selected for the fatigue analyses because of its good acceptance of data from almost all classification societies such as Germanischer Lloyd, the American Bureau of Shipping, Det Norske Veritas, etc. The maximum stress regions of the structures are obtained by using finite element analyses, and the results are compared with the endurance limit of the Wöhler diagram of AA5059 H321 aluminum alloy. The wave characteristics table given in this article is used to obtain the number of cycles for each sea condition. By using the wave characteristics table, the wave lengths, wave speeds, and cycles are obtained. This study is performed to estimate the lifetimes of a semi-swath type coast guard boat and/or commercial yacht projects, which are produced by using AA5059 H321 aluminum alloy, under different sea environment conditions. Fatigue examinations are performed for both head seas and oblique seas.
\end{abstract}

Keywords: Fatigue analysis, Palmgren-Miner's method, stress regions, wave spectrum based fatigue analysis

\section{Introduction}

Fatigue is one of the most important issues in the ship building industry. Fatigue cracks are mostly observed in commercial ships such as chemical and oil tankers, bulk carriers, etc., as a result of loading and unloading operations. However, the loads caused by waves and acceleration are the primary reasons for the occurrence of fatigue, especially in high-speed naval vessels.

Ship designers and builders have constantly been in search of alternative materials, with the aim of reducing the weight of a boat. As a result of these concerns, aluminum alloys are often seen as the most suitable materials in the ship building industry. The density of aluminum alloy AA5059 H321 is approximately $2.7 \mathrm{ton} / \mathrm{m}^{3}$ [7], while the yield stress

\footnotetext{
*Corresponding author. Tel.: + 90212 2856422, Fax.: + 902122856454

E-mail address: fuatkabakcioglu@gmail.com

Copyright $\odot$ KSOE 2013.
}

under a welded condition is $160 \mathrm{MPa}$ and under an unwelded condition is $270 \mathrm{MPa}$ [2,7]. The density of shipbuilding steel is $7.8 \mathrm{ton} / \mathrm{m}^{3}$ and the yield stress is $235 \mathrm{MPa}$. As a result of this density advantage, boats that are produced by using aluminum alloy AA5059 H321, have a significant weight advantage of up to 50\% [6]. Additionally, if we compare AA5059 H321 with AA5083 aluminum alloy in terms of strength, which is commonly used in the ship building industry, AA5059 alloy offers the possibility of building lighter boats. Another important advantage of using an aluminum alloy is the ability to obtain a considerable corrosion resistance compared to ship building steel.

Fatigue calculations are carried out considering the wave characteristics of Turkey's coastal seas. The goal of these analyses was to determine the length of time before the occurrence of a fatigue event for each sea condition and the length of the safe life time. 
Maestro software was used for all of the finite element calculations because of its quick adaptation and accurate calculation capability for different sea conditions. One of the most common and important problems in naval engineering is the calculation of the stresses caused by waves from different attack angles. Maestro makes it easier and faster to analyze the stresses caused by waves coming from different angles of attack.

\section{Palmgren-Miner Cumulative Damage Fa-}

\section{tigue Assessment}

In this study Palmgren-Miner's method was used for the fatigue analysis. Palmgren-Miner's method was chosen as the fatigue life time assessment method because a ship is exposed to stress with a variable number of cycles and amplitudes, during its life time (Fig 1).

Palmgren-Miner's method also ensures that very precise and time saving solutions can be obtained. When using this method for obtaining a cumulative damage assessment for steel specimens, all of the cycles that are above the fatigue endurance limit, should be summed. As it is shown in Figure 2[8], it is a common agreement that aluminum alloys don't have an endurance limit against a variable amplitude loading history. Hence, for aluminum specimens, all of the cycles must be taken into account to determine the fatigue endurance under such conditions.

On the basis of Figure 2, the fatigue endurance limit, which corresponds to $10^{8}$ cycles is found to be approximately $117.2 \mathrm{MPa}$ (17 ksi). According to Germanischer Lloyd Part1, Section17, Page 2, a fatigue analysis has to performed for the maximum

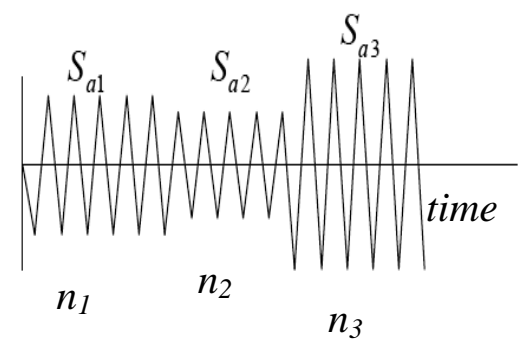

Fig. 1.Typical block loading sequence [1]. number of cycles, $N=5.10^{7}$ for seaway induced stress with a stress range spectrum [3]. For the purpose of increasing the safety limits, $N$ was taken as $10^{8}$ for this study. The annual cumulative number of cycles is obtained by the sum of the ratios of the number of cycles in each sea state to $N$ [1].

$$
\sum \frac{n}{N}=1.0
$$

Or, for the sequence in Figure 1 this would be

$$
\frac{n_{1}}{N}+\frac{n_{2}}{N}+\frac{n_{3}}{N}+\cdots=1.0
$$

where $n_{1}, n_{2}, n_{3}, \ldots$ are the numbers of cycles obtained for each sea state.

\section{Implementation of Palmgren-Miner's}

\section{Method for Turkish Territorial Waters}

The most important purpose of the fatigue analysis for a vessel is the calculation of the desired life span without any fatigue cracks or damage occurring under Aegean Sea, Mediterranean Sea and the Black Sea environmental sea conditions. Different loads will be applied to the boat by the different sea environments. Thus, depending on the sea states and sea characteristics, the fatigue stress response will be different. Table 1 presents the characteristic wave heights for different sea states and the modal wave periods are defined for the Mediterranean, the Black Sea and the Aegean Sea [5].

All of the boat calculations were performed for a displacement of 900 tons, without trim, and in a disinclined position. For 900 tons of displacement, the vessel must have a draught of $3.2 \mathrm{~m}$ and the length of the water line, which is related to the draught value, must be taken into account. Furthermore, the vessel is assumed to cruise at 20 knots $(10.28 \mathrm{~m} / \mathrm{s})$ for each case [4].

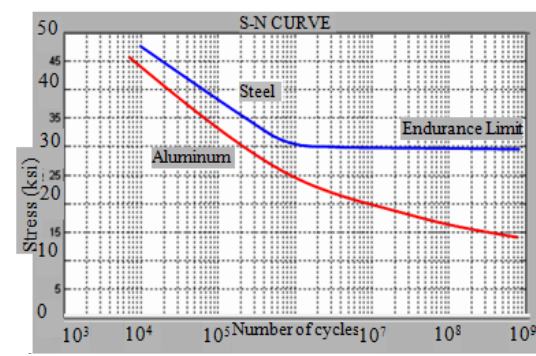

Fig. 2.Wöhler diagram of aluminum and steel specimens [8]. 
Table 1. Modal wave periods of Turkey's coastal waters [5].

\begin{tabular}{|c|c|c|c|c|}
\hline \multirow{2}{*}{$\begin{array}{c}\text { Sea } \\
\text { State }\end{array}$} & \multirow{2}{*}{$\begin{array}{c}\text { Characteris- } \\
\text { tic Wave }\end{array}$} & \multicolumn{3}{|c|}{ Modal Wave Period(sec) } \\
\cline { 3 - 5 } & Height(m) & Black Sea & $\begin{array}{c}\text { Mediterrane- } \\
\text { an Sea }\end{array}$ & $\begin{array}{c}\text { Aegean } \\
\text { Sea }\end{array}$ \\
\hline $0-1$ & 0.05 & 3.53 & 4.42 & 3.63 \\
\hline 2 & 0.3 & 4.14 & 5 & 4.01 \\
\hline 3 & 0.88 & 5.41 & 6.25 & 4.86 \\
\hline 4 & 1.88 & 7.28 & 8.15 & 6.25 \\
\hline 5 & 3.25 & 9.1 & 10.16 & 7.96 \\
\hline 6 & 5 & 10.19 & 11.74 & 9.81 \\
\hline
\end{tabular}

In these calculations, one cycle is taken to be the travel of the vessel from the crest of one wave to the crest of the next wave. The relative speed is calculated by taking into account the speeds of the wave and vessel at head and oblique seas. Wave lengths are calculated on the basis of the modal wave periods in Table 1.

\subsection{Implementation of Fatigue Analysis in Aegean Sea Cataditione $1.5178 \mathrm{~s}$.}

\subsubsection{Calculations for Aegean Sea for Sea State}

\section{Two}

When wavelength calculations are performed, the following formula (3.1) is used. In this equation, $\lambda$ is the wave height, $T$ is the wave period and $g$ is the gravitational acceleration.

$\lambda=\frac{g T^{2}}{2 \pi}$

For the purpose of calculating the wave speed, the following formula (3.2) is used. For the modal wave period of $4.01 \mathrm{~s}$ (Table1), the wave length obtained is $25.106 \mathrm{~m}$. Applying this value to equation (3.2) yields a wave speed of $6.26 \mathrm{~m} / \mathrm{s}$.

$V_{\text {wave }}=\frac{\lambda}{T}$

where $\lambda$ is the wave length, $T$ is the wave period and $V_{\text {wave }}$ is the speed of the wave. The relative speed between the boat and wave is calculated using the following formula by adding the speeds of the vessel and wave for head and oblique seas. In order to simulate the worst scenario and increase the number of cycles, it is assumed that the boat is in a head sea condition.

$V_{\text {relative }}=V_{\text {wave }}+V_{\text {boat }}$
Table 2.Characteristics of Aegean Sea

\begin{tabular}{|l|c|c|c|c|c|}
\hline \multicolumn{7}{|c|}{ Calculations For The Aegean Sea } \\
\hline $\begin{array}{c}\text { Sea } \\
\text { States }\end{array}$ & 2 & 3 & 4 & 5 & 6 \\
\hline$\lambda$ & 25.106 & $\begin{array}{c}36.877 \\
5\end{array}$ & 61 & 98.93 & $\begin{array}{c}150 . \\
3\end{array}$ \\
\hline Vwave & 6.261 & 7.588 & 9.76 & 12.43 & 15.3 \\
\hline $\begin{array}{l}\text { Vrela- } \\
\text { tive }\end{array}$ & 16.541 & 17.868 & 20 & 22.7 & 25.6 \\
\hline Cycle & $\begin{array}{c}1.423 .1 \\
12\end{array}$ & $\begin{array}{c}697.67 \\
5\end{array}$ & $\begin{array}{c}473 . \\
116\end{array}$ & $\begin{array}{c}247.93 \\
4\end{array}$ & $\begin{array}{c}183 . \\
986\end{array}$ \\
\hline
\end{tabular}

The boat's travel time from one wave crest to the next crest is calculated according to equation (3.4). The distance between two wave crests is $25.106 \mathrm{~m}$ and the relative speed is $16.541 \mathrm{~m} / \mathrm{s}$ as calculated above. By applying these values to equation (3.4), the transition time between the two wave crests is calcu-

$\lambda=V_{\text {relative }} t$

The sea state two operating duration, which is $600 \mathrm{~h}$, is equals to $2,160,000 \mathrm{~s}$. Thus, the number of cycles that the boat will be exposed to at sea state two is $1,423,112$ cycles.

\subsubsection{Calculations for Aegean Sea for Sea States}

\section{Three, Four, Five, and Six}

If the calculations that were used for sea state two are repeated for sea states three, four, five and six, the following values can be obtained and tabulated.

\subsubsection{Implementation of Palmgren-Miner's}

\section{Rule for Aegean Sea}

The cycles calculated for each sea state are taken into account cumulatively according to Palmgren Miner's rule:

$\sum \frac{n}{N} \leq 1$ 


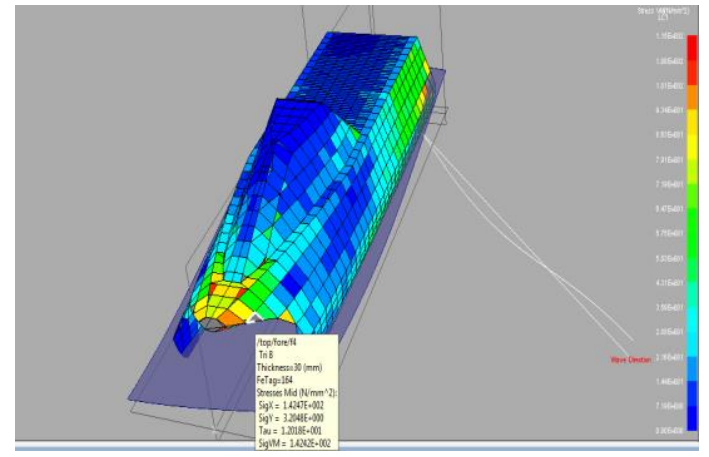

Fig. 3. Stress values caused by waves with $45^{\circ}$ angle of attack [4].

\subsection{Implementation of Fatigue Analysis under}

\section{Mediterranean Sea Conditions}

If the same annual operating time is taken as used for the Aegean Sea, the following results are obtained for the Mediterranean Sea.

\subsubsection{Implementation of Palmgren-Miner's \\ Rule for Mediterranean Sea}

When the number of cycles obtained for the Mediterranean Sea is used for equation (3.6), with $10^{8} \mathrm{cy}-$ cles as the $N$ value, 0.02111 is obtained according to Palmgren-Miner's method. By using this value, the total life time before fatigue occurrence is found to be 46.897 years.

The duration of 46.897 years again corresponds to a stress value of 117.215 MPa for $10^{8}$ cycles according to the Wöhler diagram. Stress values that exceed 117.215 MPa in the finite element model, should be

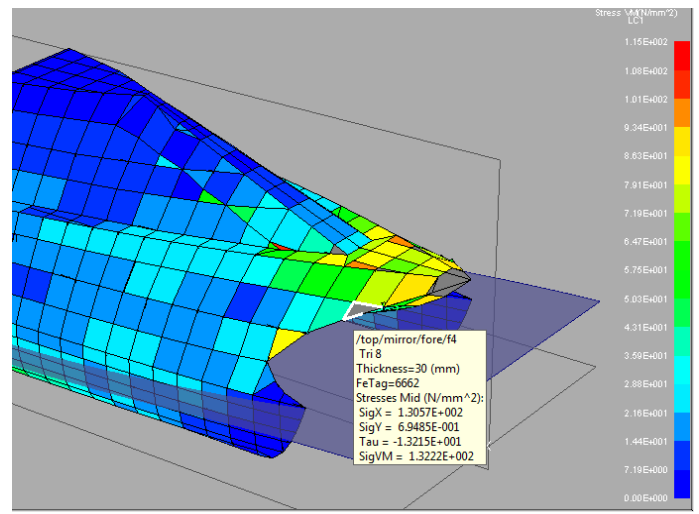

Figure 5 . Stress values caused by waves with a $45^{\circ}$ angle of attack [4].

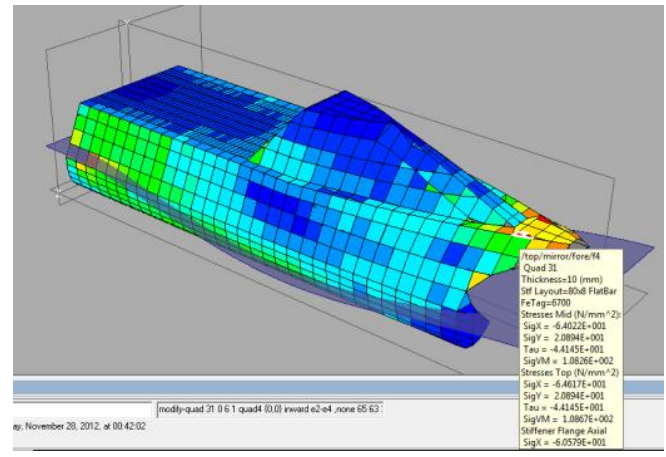

Figure 4. Stress values caused by waves with a $0^{\circ}$ (head sea) angle of attack [4].

carefully determined and the necessary structural measures should be taken.

\subsubsection{Finite Element Analysis Results for}

\section{Mediterranean Sea}

The Maestro finite element model outputs for sea state three are shown in Figures 5 and 6 as samples. According to these results, waves with a $45^{\circ}$ angle of attack (Figure 5) produce a maximum stress of 132 $\mathrm{MPa}$ in the fore and aft regions. Waves with a $0^{\circ}$ angle of attack (Figure 6) produce a maximum stress of $105 \mathrm{Mpa}$ in the fore region. In that cases, structural precautions must be considered for head seas.

\subsection{Implementation of Fatigue Analysis under}

\section{Black Sea Conditions}

Similar to the Aegean and Mediterranean Seas, the following results are obtained for the Black Sea.

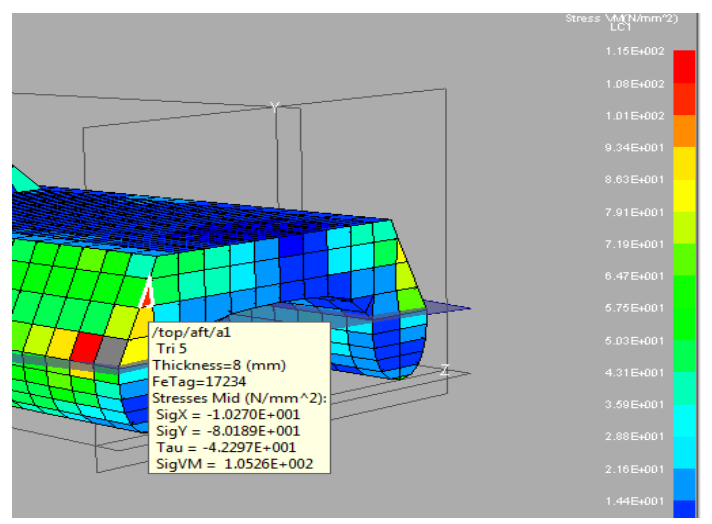

Figure 6. Stress values caused waves with a $0^{\circ}$ angle of attack [4]. 
Table 7. Calculations for Mediterranean Sea

\begin{tabular}{|l|c|c|c|c|c|}
\hline \multicolumn{7}{|c|}{ Calculations For Mediterranean Sea } \\
\hline $\begin{array}{c}\text { Sea } \\
\text { States }\end{array}$ & 2 & 3 & 4 & 5 & 6 \\
\hline$\lambda$ & 39.03 & 61 & 103.76 & 161.17 & $\begin{array}{c}215 . \\
2\end{array}$ \\
\hline \begin{tabular}{l}
$V_{\text {wave }}$ \\
\hline $\begin{array}{l}\text { Vrela- } \\
\text { tive }\end{array}$
\end{tabular} & 18.8 & 9.76 & 12.725 & 15.863 & $\begin{array}{c}18.3 \\
3\end{array}$ \\
\hline Cycle & 1.001 .623 & 473.062 & 319.291 & 175.182 & $\begin{array}{c}143.5 \\
79\end{array}$ \\
\hline
\end{tabular}

Implementing equation (3.6) for the Black Sea yields a value of 0.02698 and the resultant lifetime before fatigue occurrence is 36.69 years. Likewise, a fatigue safe stress value of $117.25 \mathrm{MPa}$ must be used in the finite element analyses performed for Black Sea cases.

\subsubsection{Finite Element Analysis Results for Black}

\section{Sea}

Maestro finite element model outputs for sea state three are shown in Figures 7 and 8 as samples. According to these results, waves with a $45^{\circ}$ angle of attack (Figure 8) has a maximum stress of $110.8 \mathrm{Mpa}$ in the fore and aft regions. Waves with a $0^{\circ}$ angle of attack (Figure 7) has a maximum stress of 143.18 in the fore region. Similarly, structural precautions has to be taken for head seas to avoid fatigue occurrence.

\section{Conclusions and Recommendations}

In this study, a semi-swath type coast guard boat, which was produced by using AA5059 H321 alloy, was analyzed for fatigue occurrence for the territorial seas of Turkey based on regional wave characteristics and wave angle of attack parameters. For the purpose of calculating the stress and hot spot areas caused by waves with different angles of attack, the Maestro finite element analysis software was used. Calculations were performed for three different sea

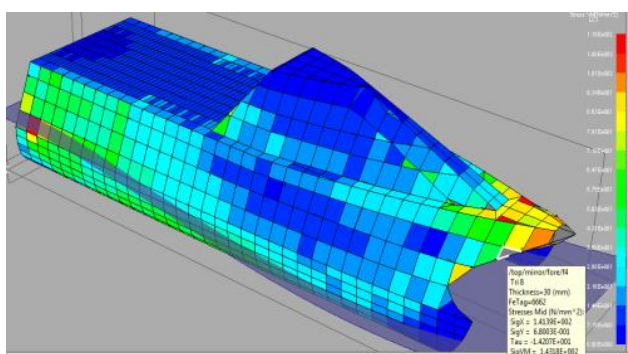

Figure 7. Stress values caused by waves with a $0^{\circ}$ (head sea) angle of attack [4].
Table 8. Design vertical accelerations at LCG

\begin{tabular}{|l|c|c|c|c|c|}
\hline \multicolumn{7}{|c|}{ Calculations For Black Sea } \\
\hline $\begin{array}{c}\text { Sea } \\
\text { States }\end{array}$ & 2 & 3 & 4 & 5 & 6 \\
\hline$\lambda$ & 26.76 & 46.69 & 82.75 & 129.3 & $\begin{array}{c}162 . \\
12\end{array}$ \\
\hline Vwave & 6.46 & 8.447 & 11.366 & 14.209 & 15.9 \\
\hline $\begin{array}{l}\text { Vrela- } \\
\text { tive }\end{array}$ & 16.74 & 18.73 & 21.647 & 24.49 & 26.2 \\
\hline Cycle & 1.351 .690 & 590.164 & 376.766 & 204.545 & $\begin{array}{c}174.4 \\
75\end{array}$ \\
\hline
\end{tabular}

regions and five different sea states. The stress values caused by waves with different angles of attack were calculated and analyzed. As a result of these analyses, how much time the boat could be used safely without taking suffering fatigue damage was predicted.

The calculations showed that, there would be no fatigue crack occurrence for 32.72 years in the Aegean Sea, 46.897 years in the Mediterranean Sea, 36.69 years in the Black Sea. If the fatigue threshold value of $117 \mathrm{Mpa}$ was not exceeded, the Aegean Sea conditions yielded the shortest period of safe use, whereas the Mediterranean Sea offered longest safe operating time.

As shown by this study, fatigue safety assessment is strongly dependent on the sea region, specific wave characteristics, angle of attack, operating hours in the sea region and building material. The variations in these parameters also changed the fatigue safe lifetime and hot spots for fatigue concerns. Therefore, it is strongly recommended that these parameters be well defined at the beginning of the design using suitable data and proper assumptions by mutual agreement between the customer and designer. After defining the applicable ranges for these parameters, a stress analysis must be performed for all cases to determine hot spots for structural improvements and the fatigue safe lifetimes.

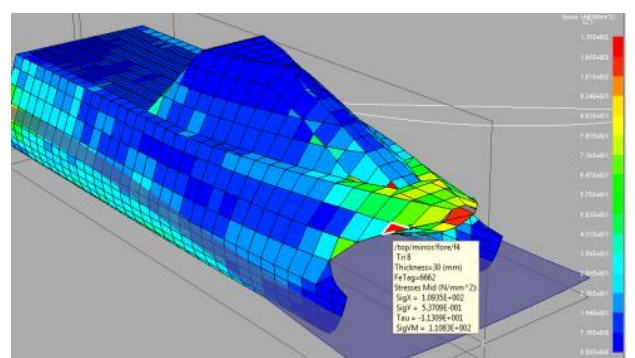

Figure 8 . Stress values caused by waves with a $0^{\circ}$ angle of attack [4]. 


\section{References}

[1] Bishop N.W.M., Sherratt F., Finite Element Based Fatigue Calculations, Chapter 4, P.33, Farnham, UK, July 2000.

[2] Ferraris S., Volpone L.M., Aluminium Alloys In Third Millenium Shipbuilding: Materials, Technologies, Perspectives, P.4,5, 11-13, October 2005 .

[3] Germanischer Lloyd, Rules for Classification and Construction, Ship Technology, Special Craft, High Speed Craft, Structures, Section 3, Chapter 1, Part 3, P. 51,July 2002.

[4] Kabakçıŏlu F., Fatigue Analysis of a SemiSwathTypeAluminum Boat with Palmgren-
Miner Method,MSc. Thesis (in Turkish), Istanbul Technical University, Graduate School of Science Engineering and Technology, 2012.

[5] Özhan E., Middle East Technical University, NATO TU-Waves Project Technical Document (1994-2002).

[6] Romhanji E., Popovic M., Problems and Prospect of Al-Mg Alloys in Marine Constructions, Association of Metallurgical Engineering of Serbia AME, P.298.

[7] SSC-464 High Speed Aluminum Vessels Design Guide, P.10, 2012.

[8] Wiki Books Advanced Structural Analysis/ Part I- Theory/ Failure Modes/ Fatigue Crack Initiation/ The Wöhler Curve. 